\title{
Penilaian Semula Pengukuran Kuantitatif Stereometri terhadap Pertumbuhan Sebatian antara Logam bagi Sambungan Pateri
}

(Reassessment of Stereometric Quantitative Measurements on the Growth of Intermetallic Compound for Solder Connections)

\author{
MARIA ABU BAKAR, AZMAN JALAR* \& ROSLINA ISMAIL
}

ABSTRAK

Pencerapan dua dimensi (2D) yang diperoleh daripada keratan rentas sampel selalunya digunakan untuk mendapatkan maklumat ketebalan lapisan sebatian antara logam (IMC). Walau bagaimanapun, pencerapan 2D amatlah terhad berbanding maklumat yang sepatutnya diperoleh daripada struktur tiga dimensi (3D) sampel. Kajian ini bertujuan untuk menilai semula kaedah pengukuran lapisan IMC daripada pemerhatian $2 D$ dengan mempertimbangkan faktor-faktor sebenar dalam bentuk 3D IMC. Nilai mod ketebalan didapati lebih mewakili nilai ketebalan IMC setelah mempertimbangkan pelbagai faktor stereometri berbanding dengan nilai purata. Ini memberikan suatu penanda aras dalam aktiviti menentukan ketebalan lapisan IMC berdasarkan pencerapan $2 D$ daripada struktur $3 D$.

Kata kunci: Ketebalan pertumbuhan sebatian antara logam; metalografi kuantitatif; pertumbuhan sebatian antara logam; stereologi

\section{ABSTRACT}

Two-dimensional observation (2D) obtained from cross-section of the sample is often used to obtain the intermetallic compound (IMC) thickness. However, 2D observation is limited compared to the information that should be obtained from a three-dimensional (3D) sample structure. This study aimed to re-evaluate the IMC layer measurement method from $2 D$ observation by considering real factors in the form of $3 D I M C$. Thickness mode values are more represent the IMC's thickness value by considering various stereometric factors as compared to average values. This provides a benchmark in the activity of determining the IMC layer thickness based on $2 D$ 's observation from the $3 D$ structure.

Keywords: Intermetallic compound growth; intermetallic compound thickness; quantitative metallography; stereology

\section{Pengenalan}

Ketebalan lapisan sebatian antara logam (IMC) merupakan kaedah yang biasa digunakan untuk penentuan pelbagai aspek dalam menilai sifat fizikal dan kebolehharapan sambungan pateri. Untuk itu, stereologi atau metalografi kuantitatif dalam bidang metalurgi telah diguna pakai bagi penentuan struktur pepejal dalam 3D matriks, saiz butiran dan lapisan sebatian antara logam (IMC) (Pabst et al. 2015; Voort 1999). Teknik metalografi kuantitatif ini dilakukan dengan menganalisis imej cerapan keratan rentas dua dimensi (2D) bagi menggambarkan struktur tiga dimensi (3D) (Uhlirova et al. 2016). Lapisan IMC terhasil daripada tindak balas metalurgi semasa proses sambungan antara aloi pateri dan substrat. Lapisan ini selalunya tumbuh membesar akibat tindakan suhu seperti selepas uji kaji piawai penyimpanan suhu tinggi (HTS) dan kitaran terma (TC). Uji kaji piawai ini merupakan uji kaji wajib dalam industri elektronik yang bertujuan untuk memastikan kualiti dan kebolehharapan sambungan pateri. Pertumbuhan lapisan IMC berlaku melalui proses resapan yang menyebabkan lapisan yang tumbuh tersebut selalunya tidak sekata daripada segi ketebalan (Yao et al.
2016). Ketidaksekataan ini menghasilkan lapisan IMC yang seakan berbentuk gunung-ganang dan lembah (Kanlayasiri \& Sukpimai 2016). Kaedah metalografi kuantitatif yang selalu digunakan untuk memerhatikan pertumbuhan lapisan IMC ialah dengan pencerapan keratan rentas melalui pelbagai jenis kaedah mikroskopi dalam mendapatkan imej 2D (Day \& Quested 1999). Seterusnya maklumat kuantitatif terpenting dalam pencerapan ini ialah perbezaan ketebalan yang disebabkan oleh berlakunya pertumbuhan IMC. Kebiasaannya dalam bidang elektronik yang melibatkan pertumbuhan lapisan IMC, nilai purata ketebalan lapisan IMC telah diterima dan diguna pakai secara meluas (Bertheau et al. 2014). Walau bagaimanapun, praktis ini tidak selaras dengan kaedah metalografi kuantitatif, dengan nisbah aspek dan faktor bentuk mestilah dipertimbangkan dalam memperihalkan sesuatu ukuran ketebalan atau struktur. Kertas ini akan menilai semula pengukuran lapisan IMC akibat pertumbuhan lapisan IMC dengan mengambil kira kedua-dua aspek iaitu daripada segi saiz dan bentuk.

Kejituan dalam pengiraan IMC adalah sangat penting kerana pewakilan nilai yang diperoleh akan digunakan 
dalam analisis lanjut, contohnya untuk mendapatkan nilai tenaga pengaktifan. Pengiraan nilai tenaga pengaktifan, $Q$ dibuat berdasarkan pertumbuhan lapisan IMC. Kadar pertumbuhan lapisan IMC dikira berdasarkan nilai ketebalan adalah seperti berikut (Feng \& Songbai 2013):

$$
x=x_{0}+\sqrt{D t}
$$

dengan ialah ketebalan IMC; ketebalan awal IMC; ialah pemalar kadar pertumbuhan yang bergantung kepada suhu; dan ialah masa penuaan. Seterusnya, nilai kadar pertumbuhan ini digunakan dalam rumus tenaga pengaktifan seperti berikut:

$$
D=D_{0} \exp \left(-\frac{Q}{R T}\right)
$$

dengan ialah pemalar kadar pertumbuhan; ialah faktor frekunsi; ialah tenaga pengaktifan bagi pertumbuhan lapisan antara muka IMC; ialah pemalar gas $(8.314 \mathrm{~kJ} /$ mol K); dan ialah suhu dalam unit Kelvin (K). Dengan ini, didapati nilai $d$ yang digunakan adalah hasil daripada pengiraan nilai purata ketebalan (Gancarz \& Pstrus 2015). Liang et al. (2016) telah melaporkan pengukuran ketebalan IMC sebagai wakil pertumbuhan IMC. Pengiraan ketebalan IMC digunakan secara meluas bagi pengiraan pertumbuhan IMC atau perwakilan saiz IMC. An dan Qin (2014) mengira purata ketebalan IMC dengan menggunakan analisis imej secara kuantitatif. Purata ketebalan diperoleh dengan mendapatkan nilai luas cerapan lapisan IMC, kemudian dibahagikan dengan panjang lapisan kawasan cerapan IMC. Zou et al. (2008) pula telah menggunakan perisian khas untuk mengira purata ketebalan lapisan IMC dengan menggunakan (3):

$$
T=\int_{0}^{D_{0}} \frac{f(x) d x}{L_{0}}
$$

dengan adalah panjang kawasan yang dikira; ialah fungsi kontur IMC; dan ialah purata ketebalan lapisan IMC. Kajian daripada An dan Qin (2014) telah menggunakan (4) untuk mengira purata ketebalan IMC:

$$
d=\frac{A}{L}
$$

dengan $d$ ialah purata ketebalan; manakala ialah luas dan ialah panjang lapisan IMC.

Nilai purata ketebalan, $d$ yang selalunya dicerapkan tidak mempertimbangkan bentuk gunung-ganang dan lembah yang terhasil. Sekiranya sesuatu bentuk gunungganang yang terlalu tinggi atau lembah yang terlalu dalam

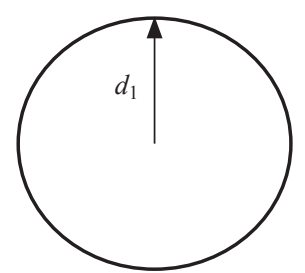

(a)

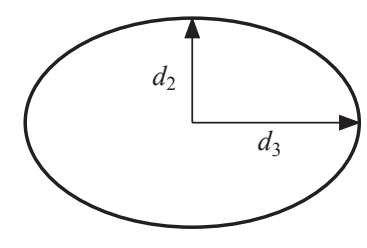

(b)
RAJAH 1. Ilustrasi bentuk struktur 2D (a) bulat dan (b) bujur dicerap, sudah tentu ia akan mempengaruhi nilai purata ketebalan. Hal ini juga berkait rapat dengan lokasi untuk mendapatkan keratan rentas melalui proses pemotongan sampel sebagai kawasan pengukuran yang hendak dilakukan. Faktor bentuk adalah sangat perlu untuk diambil kira. Contohnya, pertimbangkan imej 2D dalam Rajah 1 yang mempunyai keluasan yang sama tetapi bentuk yang berlainan. Didapati bagi struktur (a) mempunyai pintasan $d_{1}$ manakala struktur (b) mempunyai pintasan $d_{2}$ dan $d_{3}$ dengan Maka, dalam memperihalkan struktur (a) dan (b), kaedah metalografi kuantitatif digunakan dengan mempertimbangkan faktor bentuk untuk mengadaptasikan nilai $d$ berserta nisbah aspek.

Walau bagaimanapun, berdasarkan keputusan kajian lepas secara kuantitatifnya, pencerapan 2D bagi pemerihalan kriteria struktur 3D amatlah tidak meyakinkan. Maka, kajian ini adalah perlu untuk menilai semula kaedah pengukuran pertumbuhan sebatian antara logam dengan mempertimbangkan juga aspek statistik pengambilan bacaan selain faktor pengukuran menurut kaedah metalografi kuantitatif.

\section{BAHAN DAN KAEDAH}

Kaedah pengukuran kebiasaannya hanya menggunakan pencerapan imej 2D bagi mendapatkan maklumat berkaitan mikrostuktur seperti ketebalan, luas dan bentuk. Kajian ini menggunakan alat pengukur fokus tidak terhingga (Alicona), IFM untuk mencerap mikrostruktur pertumbuhan IMC. Alat IFM bertindak sebagai penganalisis imej, mencerap imej yang lebih baik daripada mikroskop optik dengan pengimbasan seluruh permukaan sampel dengan resolusi tinggi dan imej topografi dengan pembesaran sebanyak $100 \times$. Alat ini berkemampuan untuk menganalisis mikrostruktur secara $2 \mathrm{D}$ dan 3D, mengukur profil permukaan, kekasaran, kegelombangan, tekstur, isi padu dan pengukuran sisi. Kajian ini mengukur ketebalan IMC melalui cerapan morfologi IMC pada bahagian keratan rentas menggunakan pengukuran dalam bentuk garisan. Untuk melihat perubahan pertumbuhan dan ketebalan IMC, sambungan pateri SAC 0307 (99\% Sn, 0.3\% Ag, 0.7\% $\mathrm{Cu}$ ) didedahkan kepada uji kaji penuaan pada suhu $150^{\circ} \mathrm{C}$ selama 200 jam mengikut piawai JEDEC (JESD22-A103C). Selesai proses pengujian penuaan, teknik metalografi digunakan untuk mendapatkan keratan rentas sampel bagi tujuan pencerapan mikrostruktur pertumbuhan sebatian antara logam (IMC). Teknik metalografi bermula dengan pemotongan sampel, proses cagak, proses lelasan dan proses penggilapan bagi mendapatkan permukaan sampel yang bebas calar (Bakar et al. 2016). Selesai proses metalografi, sampel akan dianalisis dengan menggunakan alat IFM. Rajah 2 menunjukkan ilustrasi skematik cara pengukuran ketebalan IMC. Untuk mengukur ketebalan IMC melalui keratan rentas sampel, kawasan dan bentuk pertumbuhan IMC yang sesuai dipilih. Garis kiraan adalah dari sempadan atas IMC dan sempadan atas substrat dan dalam keadaan berserenjang atau pada sudut $90^{\circ}$. Ini adalah untuk memastikan garisan ukuran adalah lurus. Ketebalan IMC diukur dengan mengambil pengukuran 


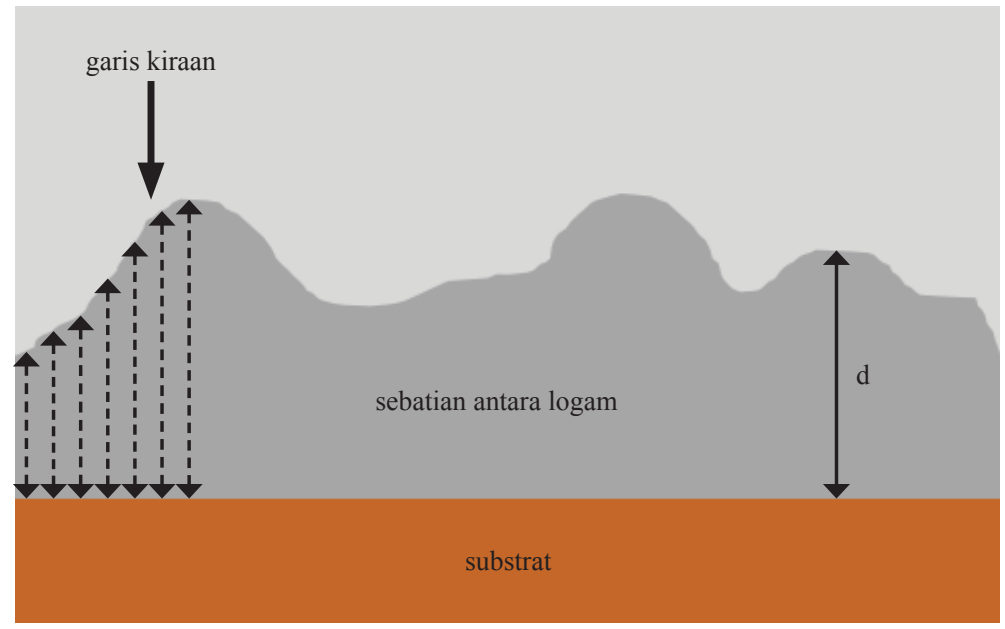

RAJAH 2. Illustrasi skematik kaedah pengukuran ketebalan sebatian antara logam

ketebalan sebanyak 300 bacaan pada garisan ukuran yang berlainan. Data ketebalan IMC kemudian dianalisis untuk mendapatkan nilai purata, mod dan median. Nilai ini dijalankan analisis lanjut dengan mengambil kira faktor bentuk IMC yang tidak seragam.

\section{KePUTUSAN DAN PERBINCANGAN}

Isu yang penting dalam menganalisis nilai ketebalan IMC akan mempengaruhi analisis lanjut yang sangat bergantung kepada cara pengukuran ketebalan IMC. Kaedah pengukuran pencerapan imej 2D melalui teknik metalografi kuantitatif dilakukan untuk mendapatkan maklumat pertumbuhan 3D. Rajah 2 menunjukkan bentuk lapisan IMC yang tumbuh sebelum dan selepas didedahkan kepada uji kaji penuaan pada $150^{\circ} \mathrm{C}$ selama 200 jam. Didapati bentuk struktur lapisan yang tumbuh sebelum dan selepas uji kaji penuaan adalah tidak seragam, berbentuk lembah dan bergunung-ganang. Pengukuran ketebalan terhadap lapisan IMC daripada keratan rentas ditunjukkan dalam Rajah 3 berdasarkan purata, median dan mod, telah memberikan nilai yang berbeza. Pemilihan jenis pengukuran ketebalan adalah sangat penting dan seharusnya boleh digunakan untuk menggambarkan bentuk struktur IMC yang tumbuh. Nilai purata boleh dipilih untuk mewakilkan pertumbuhan IMC sekiranya bentuk lapisan IMC adalah seragam yang memberi implikasi bahawa pertumbuhan yang berlaku adalah seragam dan bersifat
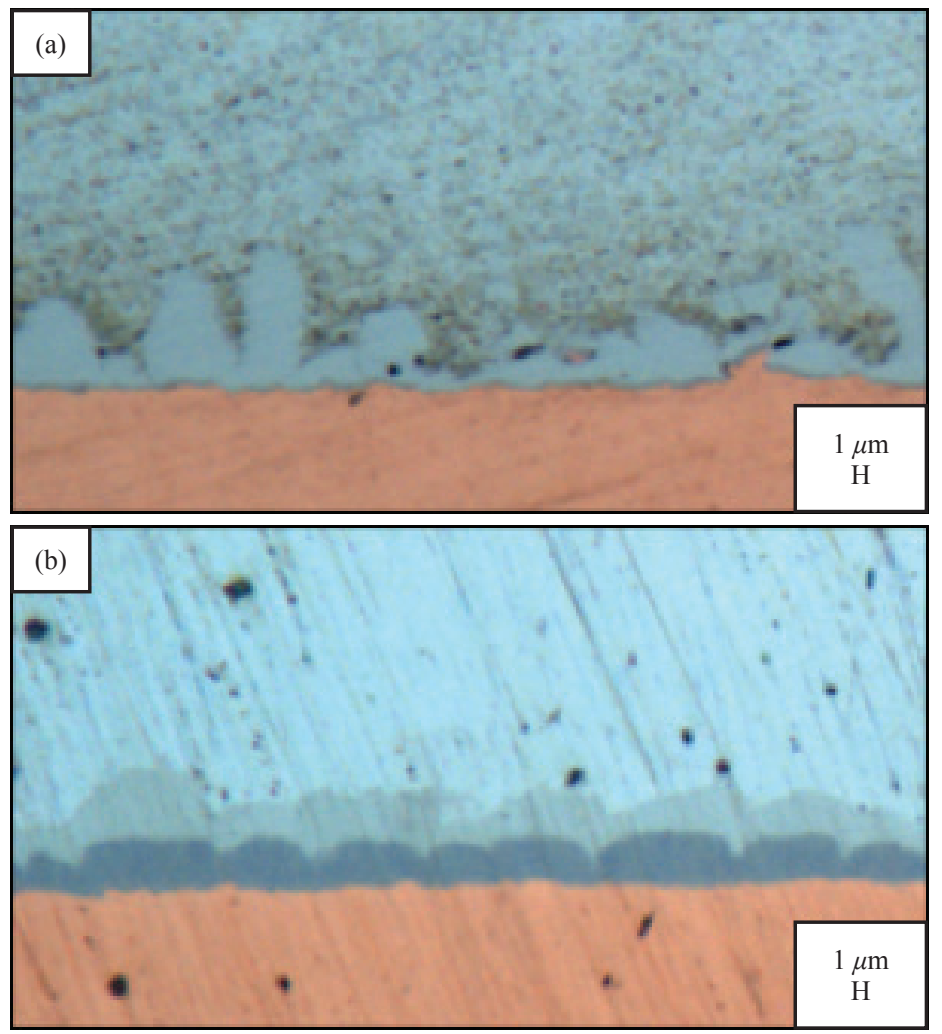

RAJAH 3. Mikrograf bagi SAC 0307 pada $\mathrm{PCB} / \mathrm{Cu}$ (a) sebelum dan (b) selepas uji kaji penuaan pada suhu $150^{\circ} \mathrm{C}$ selama 200 jam 
tidak memilih yang bermaksud bahawa pertumbuhan yang homogen, tidak dipengaruhi oleh faktor metalurgi terutama yang melibatkan sifat tidak isotrop (anisotropi) dalam pembentukan IMC. Nilai median belum pernah dilaporkan dalam mewakili ketebalan IMC untuk bahan sambungan elektronik. Adalah berkemungkinan nilai median boleh digunakan sekiranya bentuk gunung dan lembah yang keterlaluan diabaikan. Walau bagaimanapun, nilai bentuk gunung dan lembah yang lampau mesti diambil kira kerana melibatkan tindak balas pertumbuhan IMC yang bersifat memilih terhadap unsur tindak balas (dalam kes ini logam substrat-logam pateri) dan juga lokasi tindak balas contohnya bergantung kepada orientasi kristalografi. Nilai ketebalan yang diwakili oleh mod mengambil kira kekerapan nilai pengukuran berdasarkan tempat pengukuran yang diambil. Sekiranya tempat pengukuran yang diambil lebih pada kawasan gunung-ganang, maka nilai mod menjurus kepada perwakilan gunung-ganang. Begitu juga sekiranya pengukuran pada kawasan lembah, maka dapatan pengukuran akan mewakili nilai ketinggian lembah. Jika digabungkan nilai pengukuran kesemuanya, maka keputusan nilai purata yang mana tidak diketahui sama ada mewakilkan kawasan gunung ganang ataupun kawasan lembah. Analisis lanjut menunjukkan berdasarkan Rajah 3, jenis pengukuran ketebalan yang sesuai dan dicadangkan untuk mewakilkan ketebalan IMC untuk pertumbuhan yang tidak sekata ialah mod. Hal ini adalah kerana mod mewakili kekerapan ketebalan yang hadir dalam pengiraan IMC dan sesuai untuk mewakilkan tebal IMC atas sebab mempertimbangkan faktor bentuk IMC yang tumbuh yang mempunyai lembah dan bergunung-ganang. Jelas bahawa pemilihan jenis pengukuran ketebalan akan memberikan implikasi kuantitatif terhadap perwakilan nilai IMC. Pengukuran dan penentuan nilai pertumbuhan IMC ini adalah sangat kritikal kerana data nilai IMC ini banyak digunakan dalam mengakses kualiti sambungan contohnya dalam menjangkakan kebolehharapan atau jangka hayat sesuatu sambungan elektronik.

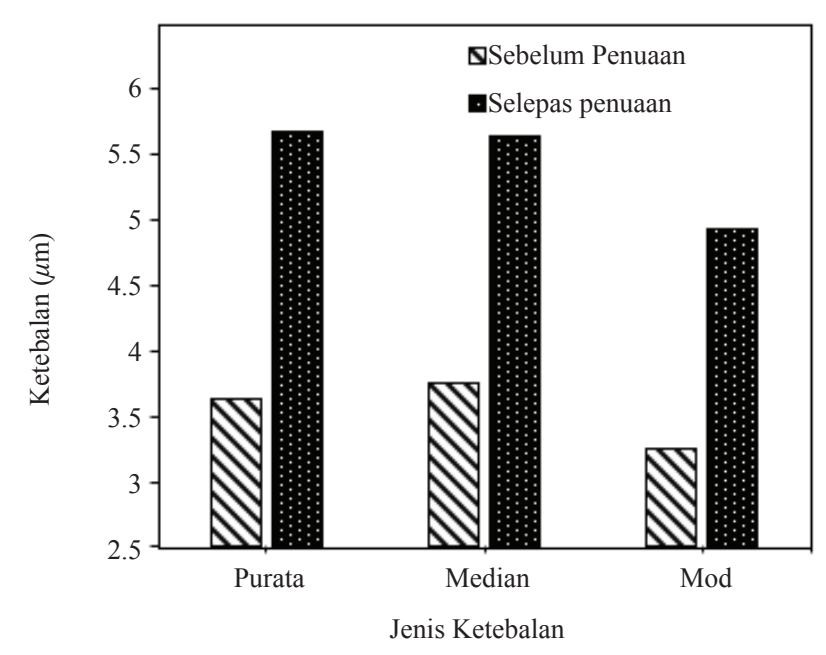

RAJAH 4. Nilai ketebalan IMC bagi SAC 0307 pada $\mathrm{PCB} / \mathrm{Cu}$ sebelum dan selepas uji kaji penuaan pada suhu $150^{\circ} \mathrm{C}$ selama $200 \mathrm{jam}$
Dalam kajian ini, sekurang-kurangnya 300 bacaan nilai ketebalan telah diambil kerana faktor ralat statistik diminimumkan bagi perwakilan nilai seperti dalam Rajah 2. Jika melihat hasil kajian lepas dalam mendapatkan purata ketebalan, pengukuran bacaan yang diambil adalah sekitar 9-30 bacaan (Alam \& Chan 2005; Hang et al. 2008; Kammerer et al. 2015; Nishikawa \& Iwata 2015; Yoon et al. 2005; Zhao et al. 2006). Di sini timbul persoalan, adakah jumlah titik bacaan yang diambil mencukupi dan boleh menggambarkan ketebalan lapisan IMC sedangkan lapisan IMC yang tumbuh jelas tidak sekata. Walaupun terdapat laporan yang menggunakan sehingga frekuensi di bawah 30 bacaan untuk mewakili nilai bacaan yang dicerap, namun hal ini boleh diguna pakai jika bentuk suatu struktur atau fasa, contohnya pengiraan butiran atau ira (ASTM E112) berbentuk ekapaksi iaitu dengan faktor bentuk mempunyai nisbah aspek $\sim 1$ (Lindqvist \& Akesson 2001). Analogi ini boleh digunakan sekiranya pertumbuhan lapisan IMC adalah seragam atau tidak dipengaruhi oleh faktor bentuk. Tambahan lagi, dalam kajian yang melibatkan pertumbuhan IMC bagi sambungan elektronik, didapati pertumbuhannya adalah tidak seragam. Maka, adalah amat meragukan jika garisan bacaan yang dilakukan berfrekuensi lebih kurang 30. Dalam analisis ini, faktor bentuk telah diambil kira dengan membuat pengukuran pada frekuensi 300. Maka, pengukuran nilai ketebalan berdasarkan perwakilan mod diadaptasi setelah mengambil kira bentuk, lokasi dan mekanisme pertumbuhan yang tidak seragam. Tambahan pula, perwakilan purata yang diguna pakai sebagai nilai pertumbuhan IMC telah mengabaikan faktor bentuk dan struktur IMC.

Daripada perspektif pensampelan iaitu isu pemotongan sampel bagi penentuan pemilihan keratan rentas. Pertimbangkan bahan pateri yang dilekatkan atau disambungkan pada substrat membentuk suatu struktur seperti skematik bentuk gunung ganang 3D yang digambarkan di dalam Rajah 5. Sebelum pemerhatian terhadap mikrostrukur keratan rentas (seperti di dalam Rajah 2 dan 3), pemilihan kawasan untuk pemotongan adalah sangat kritikal. Kebiasaannya penyelidik akan membuat keratan rentas pada bahagian diameter atau garis pusat terpanjang. Sekiranya sampel berbentuk wayar atau kepingan, ada asas yang boleh membantu untuk mendapatkan kawasan pemerhatian (keratan rentas) yang boleh mewakili sampel. Contohnya jika kepingan logam, terdapat arah gelekkan ataupun bagi wayar, pemotongan dilakukan pada arah terikan. Manakala bagi sampel dalam bidang kimpalan, pemotongan dilakukan pada arah kimpalan atas sebab sifat logam yang tidak isotrop. Maka dalam hal pematerian, contohnya bagi kes bebola pateri yang tidak ada arah yang boleh digunakan sedangkan ia juga masih tertakluk kepada sifat tidak isotrop. Maka, didapati pemotongan sampel yang paling sesuai adalah secara rawak dalam mendapatkan kawasan keratan rentas. Garis melintang di dalam skematik Rajah 5 iaitu di tengah kawasan gunung ganang tersebut digunakan untuk memotong sampel bagi mendapatkan kawasan keratan rentas gunung-ganang. Pertimbangkan garisan pemotongan (a) telah menghasilkan bentuk stuktur seperti a, garisan 
(b)

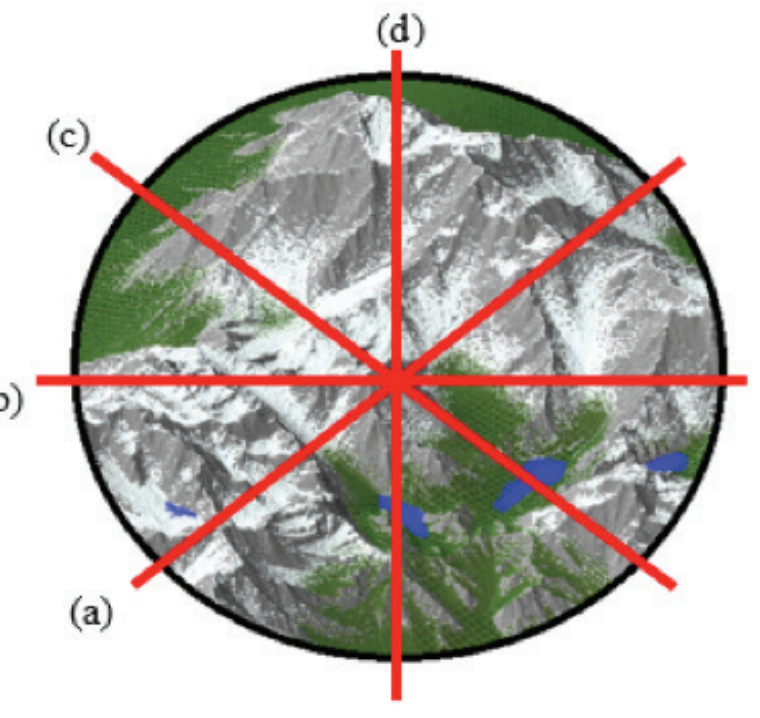

(a)
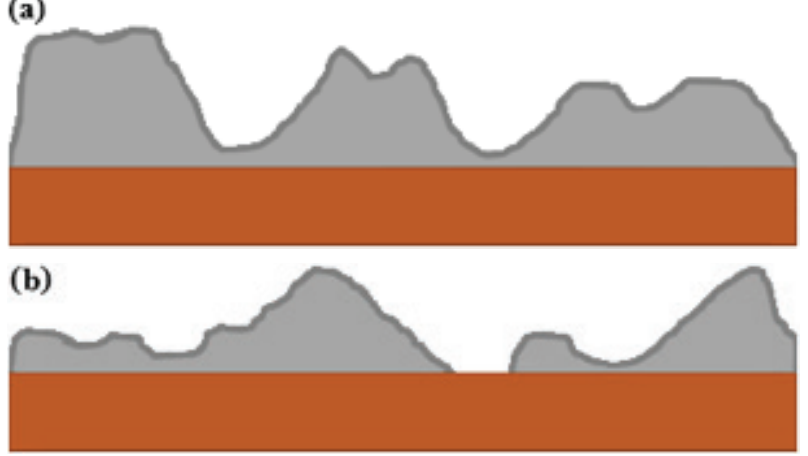

(c)
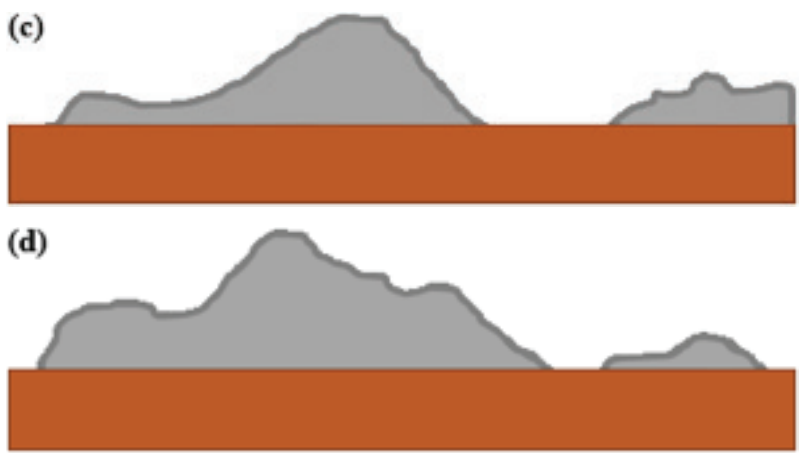

RAJAH 5. Skematik garisan pemotongan untuk mendapatkan kawasan rentas pada kawasan gunung ganang 3D (a) keratan rentas garisan a (b) keratan rentas garisan b dan (c) keratan rentas garisan $\mathrm{c}$ dan $(\mathrm{d})$ keratan rentas garisan $\mathrm{d}$

(b) menghasilkan struktur b, garisan (c) menghasilkan struktur c dan garisan (d) menghasilkan struktur d. Walau bagaimanapun, pemotongan secara rawak bagi mendapatkan keratan rentas ini telah memberikan keratan rentas dengan struktur bentuk pertumbuhan yang berbezabeza. Keadaan ini menjelaskan mengapa keputusan pengukuran ketebalan IMC di dalam Rajah 4 daripada segi purata, mod dan median telah memberikan nilai yang berbeza-beza. Pemilihan lokasi pengukuran turut memberi kesan kerana pengukuran ketebalan IMC dilakukan pada kawasan keratan rentas yang sangat bergantung kepada proses metalografi iaitu proses pemotongan sampel. Kajian ini cenderung untuk memilih jenis mod untuk mewakili ketebalan IMC kerana mod merupakan nilai yang paling kerap hadir dalam bacaan ketebalan dan sesuai bagi mewakili pertumbuhan kerana bentuk IMC yang mempunyai lembah serta bergunung-ganang.

\section{KESIMPULAN}

Secara praktisnya, penentuan ketebalan lapisan IMC yang diamalkan secara meluas perlu dinilai semula dengan mengambil kira faktor-faktor statistik pengukuran, faktor bentuk (nisbah aspek), lokasi pengukuran serta teknik persampelan yang betul (menjurus kepada pemilihan kawasan pemotongan sampel). Nilai ketebalan lapisan IMC didapati lebih sesuai untuk diwakili oleh nilai mod, berbanding nilai purata dan median, setelah mempertimbangkan faktor yang dinyatakan. Adalah dicadangkan supaya nilai pengukuran mod diguna pakai dalam menentukan ketebalan lapisan yang tidak sekata, seperti lapisan IMC yang tumbuh akibat tindakan terma.

\section{PENGHARGAAN}

Penulis merakamkan penghargaan kepada pihak RedRing Solder (M) Sdn. Bhd. atas kolaborasi projek ini serta sumbangan bahan penyelidikan dan Universiti Kebangsaan Malaysia (UKM) untuk geran penyelidikan DIP-2014-012.

\section{RUJUKAN}

Alam, M.O. \& Chan, Y.C. 2005. Solid-state growth kinetics of $\mathrm{Ni}_{3} \mathrm{Sn}_{4}$ at the $\mathrm{Sn}-3.5 \mathrm{Ag}$ solder/Ni interface. Journal of Applied Physics 98: 123527.

An, T. \& Qin, F. 2014. Effects of the intermetallic compound microstructure on the tensile behavior of $\mathrm{Sn} 3.0 \mathrm{Ag} 0.5 \mathrm{Cu} /$ $\mathrm{Cu}$ solder joint under various strain rates. Microelectronics Reliability 54: 932-938.

Bakar, M.A., Jalar, A., Daud, A.R., Ismail, R., Lah, N.C.A. \& Ibrahim, N.S. 2016. Nanoindentation approach on investigating micromechanical properties of joining from green solder materials. Sains Malaysiana 45(8): 1275-1279.

Bertheau, J., Hodaj, F., Hotellier, N. \& Charbonnier, J. 2014. Effect of intermetallic compound thickness on shear strength of $25 \mathrm{~mm}$ diameter Cu-pillars. Intermetallics 51: 37-47.

Day, A.P. \& Quested, T.E. 1999. A comparison of grain imaging and measurement using horizontal orientation and colour orientation contrast imaging, electron backscatter pattern and optical methods. Journal of Microscopy 195(3): 186196.

Feng, J. \& Songbai, X. 2013. Growth behaviors of intermetallic compound layers in $\mathrm{Cu} / \mathrm{Al}$ joints brazed with $\mathrm{Zn}-22 \mathrm{Al}$ and $\mathrm{Zn}-22 \mathrm{Al}-0.05 \mathrm{Ce}$ filler metals. Materials and Design 51: 907-915.

Gancarz, T. \& Pstrus, J. 2015. Formation and growth of intermetallic phases at the interface in the $\mathrm{Cu} / \mathrm{Sn}-\mathrm{Zn}-\mathrm{Ag}$ $\mathrm{Cu} / \mathrm{Cu}$ joints. Journal of Alloys and Compounds 647: 844-856.

Hang, C.J., Wang, C.Q., Mayer, M., Tian, Y.H., Zhou, Y. \& Wang, H.H. 2008. Growth behavior of $\mathrm{Cu} / \mathrm{Al}$ intermetallic compounds and cracks in copper ball bonds during isothermal aging. Microelectronics Reliability 48 : 416-424. 
Kammerer, C.C., Behdad, S., Zhou, L., Betancor, F., Gonzalez, M., Boesl, B. \& Sohn, Y.H. 2015. Diffusion kinetics, mechanical properties, and crystallographic characterization of intermetallic compounds in the $\mathrm{Mg}-\mathrm{Zn}$ binary system. Intermetallics 67: 145-155.

Kanlayasiri, K. \& Sukpimai, K. 2016. Effects of indium on the intermetallic layer between low-Ag SAC0307-xIn lead-free solders and Cu substrate. Journal of Alloys and Compounds 668: 169-175.

Lindqvist, J.E. \& Akesson, U. 2001. Image analysis applied to engineering geology, a literature review. Bull. Eng. Geol. Env. 60: 117-122.

Pabst, W., Gregorova, E. \& Uhlirova, T. 2015. Microstructure characterization via stereological relations - A shortcut for beginners. Materials Characterization 105: 1-12.

Nishikawa, H. \& Iwata, N. 2015. Formation and growth of intermetallic compound layers at the interface during laser soldering using $\mathrm{Sn}-\mathrm{Ag} \mathrm{Cu}$ solder on a $\mathrm{Cu}$ Pad. Journal of Materials Processing Technology 215: 6-11.

Uhlirova, T., Pabst, W., Gregorova, E. \& Hostasa, J. 2016. Stereology of dense polycrystalline materials - from interface density and mean curvature integral density to Rayleigh distributions of grain sizes. Journal of the European Ceramic Society 36: 2319-2328.

Voort, G.F.V. 1999. Metallography Principles and Practice. ASM International. Lake Bluff, Illinois.
Yao, Y., Zhou, J., Xue, F. \& Chen, X. 2016. Interfacial structure and growth kinetics of intermetallic compounds between Sn-3.5Ag solder and Al substrate during solder process. Journal of Alloys and Compounds 682: 627-633.

Yoon, J.W., Kim, S.W. \& Jung, S.B. 2005. Interfacial reaction and mechanical properties of eutectic $\mathrm{Sn}-0.7 \mathrm{Cu} / \mathrm{Ni} \mathrm{BGA}$ solder joints during isothermal long-term aging. Journal of Alloys and Compounds 391: 82-89.

Zhao, J., Yang, P., Zhu, F. \& Cheng, C.Q. 2006. The effect of high magnetic field on the growth behaviour of $\mathrm{Sn}-3 \mathrm{Ag}-0.5 \mathrm{Cu} /$ Cu IMC layer. Scripta Materialia 54: 1077-1080.

Zou, H., Zhu, Q. \& Zhang, Z. 2008. Growth kinetics of intermetallic compounds and tensile properties of Sn-Ag$\mathrm{Cu} / \mathrm{Ag}$ single crystal joint. Journal of Alloys and Compounds 461: 410-417.

Pusat Pengajian Fizik Gunaan

Fakulti Sains dan Teknologi

Universiti Kebangsaan Malaysia

43600 UKM Bangi, Selangor Darul Ehsan

Malaysia

*Pengarang untuk surat-menyurat; email: azmn@ukm.edu.my

Diserahkan: 29 Ogos 2017

Diterima: 10 November 2017 